\title{
Hidbokas: Pemanfaatan Botol Bekas Sebagai Media Tanam Hidroponik pada PKH Desa Ngadirejo Magetan
}

\author{
Krisna Robitara Aji ${ }^{1}$, Taufik Dian Murseto ${ }^{2}$, Feisal Hafidz ${ }^{3}$, \\ Te'o Kinaldhi ${ }^{4}$, Rahmat Gutomo ${ }^{5}$, Dian Pratiwi ${ }^{6}$ \\ ${ }^{1-3}$ Mahasiswa Fakultas Ekonomi, Universitas Merdeka Madiun, Jl.Serayu 79, Madiun, 63133 \\ E-mail:taraaji71@gmail.com \\ ${ }^{4}$ Mahasiswa Program Studi Teknik Sipil, Fakultas Teknik, Universitas Merdeka Madiun, Jl.Serayu 79, Madiun, 63133 \\ E-mail:taraaji71@gmail.com \\ ${ }^{5}$ Mahasiswa Program Studi Agroteknologi, Fakultas Pertanian, Universitas Merdeka Madiun, Jl.Serayu 79, Madiun, 63133 \\ E-mail:taraaji71@gmail.com \\ ${ }^{6}$ Dosen Program Studi Manajemen Fakultas Ekonomi, Universitas Merdeka Madiun, Jl.Serayu 79, Madiun, 63133 \\ E-mail:dianpratiwi@unmer-madiun.ac.id
}

\begin{abstract}
Hydroponic training activities were held in the village of Ngadirejo Magetan. Activity participants were PKH members in the village. PKH (Program Keluarga Harapan) or in international is similar with Conditional Cash Transfers (CCT) is a program from government to help poor families .All participants were enthusiastic in participating in the training. Armed with hydroponic cultivation skills, it is expected that the community can use plastic bottle waste for planting media. in addition, this activity can also generate income for the community, especially housewives.
\end{abstract}

Keywords - : hydroponic; bottles; PKH.

\section{PENDAHULUAN}

Desa Ngadirejo Kec. Kawedanan Magetan tergolong desa dengan penduduk yang padat, dengan luas wilayah $1,62 \mathrm{~km}^{2}$. Penduduk Desa Ngadirejo sebagian besar memiliki tingkat ekonomi menengah ke bawah dengan mayoritas bekerja sebagai petani. Sebagian lainnya adalah mereka yang merupakan petani penggarap atau buruh tani yang bekerja di lahan milik orang lain. Sebagaimana desa-desa lainnya, di Desa Ngadirejo juga terdapat program pemerintah yang bernama PKH (Program Keluarga Harapan), sebagai salah satu program percepatan penanggulangan kemiskinan yang digagas oleh Kementerian Sosial Republik Indonesia. Di Desa tersebut program ini membentuk sebuah kelompok yang aktif melakukan kegiatan rutin serta melaksanakan kegiatan usaha bersama untuk melatih kemandirian ekonomi seperti usaha dibidang pembuatan kerupuk untuk dapat membantu peningkatan pendapatan anggotanya. Namun begitu, kegiatan kelompok tersebut dirasa masih kurang sehingga perlu untuk diberikan kegiatan lain sebagai variasi dengan memanfaatkan potensi yang ada dengan lebih produktif.

Banyaknya limbah botol bekas di Desa Ngadirejo yang belum bisa dimanfaatkan dengang baik dapat berpotensi mencemari lingkungan. Botol bekas merupakan salah satu limbah yang sulit terurai namun sangat bisa didaur ulang. Limbah apabila bisa dimanfaatkan dengan baik pasti akan menjadi suatu nilai yang bermanfat. Selain didaur ulang untuk dihancurkan dan diolah kembali, botol plastik juga bisa dimanfaatkan sebagai media tanam.

Hidroponik adalah aktivitas pertanian yang dijalankan menggunakan air sebagai medium untuk menggantikan tanah (Istiqomah, 2006). Sistem hidroponik yang mengunakan bahan botol bekas yang berukuran 1.5 liter akan sangat efesien dan dapat mengurangi sampah plastik rumah tangga yang ada di lingkungan masyarakat. Konsep 3R (reduce, reuse, recycle) merupakan bentuk kegiatan yang sangat mungkin dilaksanakan dalam pengelolaan sampah. Konsep 3R adalah merupakan dasar dari berbagai usaha untuk mengurangi limbah sampah dan mengoptimalkan proses produksi sampah (Suryanto dkk., 2005).

Temuan metode hidroponik terbaru yang saat ini sudah terbukti menguntungkan adalah metode NFT dan metode aeroponik. (Lingga, 2002). Hidroponik mengguanakan metode NFT (nutrient film tecnique) adalah menanam tanaman pada styrofoam yang dipasang pada wadah berupa talang air. Dalam talang air tersebut dialiri dengan larutan nutrisi sebagai unsur hara. Selanjutnya larutan hara tersebut akan diserap oleh tanaman sebagai nutrisi.

Hidroponik menggunakan metode aeroponik, metode ini digunakan dengan cara menyemprotkan nutrisi berupa unsur hara langsung ke akar tanaman yang tumbuh menggantung.

Melalui kelompok PKH ini potensi dalam perwujudan tanaman hidroponik dari botol bekas di Desa Ngadirejo sangat berpeluang untuk dikembangkan. Selain untuk meningkatkan kreativitas warga masyarakat juga untuk mengurangi sampah berupa botol bekas yang dihasilkan dari limbah sisa, dengan jumlah penduduk yang padat di Desa Ngadirejo disana mudah untuk mencari limbah-limbah dari botol bekas. Dengan langkah pemanfaatan limbah botol bekas ini maka permasalahan sampah yang ada di masyarakat bisa berkurang dan bisa menciptakan ekonomi kreatif untuk menjadikan masyarakat desa menjadi lebih mandiri, dan bisa menjadi desa percontohan dengan memanfaatkan limbah bekas menjadi media hidroponik. 
Website : http://dayamas.unmermadiun.ac.id/index.php/dayamas

\section{METODE PENELITIAN}

Kegiatan PKM Pengabdian Kepada Masyarakat ini dilaksanakan dalam beberapa kali tatap muka. Kelompok PKH yang terlibat terdiri atas 25 peserta. Dengan rentang usia antara 35-67 tahun. Pelaksanaan kegiatan diawali pada tanggal 13 Mei 2018. Peserta pertama kali diberikan penjelasan tentang apa itu hidroponik, bagaimana memanfaatkan barang-barang bekas di sekitar sebagai media tanam hidroponik, serta bagaimana hidroponik dapat menjadi salah satu sumber pendapatan masyarakat yang sangat potensial untuk dikembangkan.

Kegiatan selanjutnya adalah dengan pelatihan pembuatan HIDBOKAS, dimana tim langsung terjun mempraktikkan cara membuat Hidroponik dari Botol Bekas. Setelah pembuatan HIDBOKAS tim memberikan pelatihan materi tentang perawatan HIDBOKAS dimana tim memberikan materi tentang bagaimana cara merawat HIDBOKAS supaya tumbuh dengan baik. Kemudian kegiatan selanjutnya tim memberikan pelatihan tentang kewirausahaan dan langsung mengaplikasikannya kepada masyarakat.

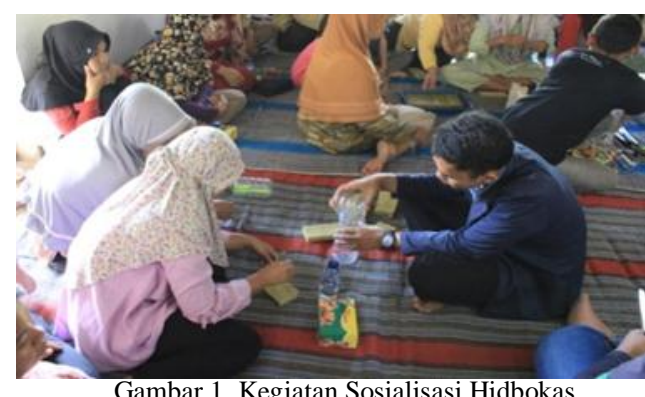

Pelaksana memberikan pelatihan tentang pembuatan media tanam hidroponik dengan memanfaatkan botol bekas, teknisnya dari seluruh peserta yang hadir akan kami bagi menjadi sepuluh kelompok kemudian membuat media tanam tersebut secara bersama-sama dengan arahan dari pelaksana. Peserta mengaplikasikannya secara langsung dengan menggunakan peralatan dan bahan yang telah kami persiapkan sebelumnya. Masing-masing kelompok akan didampingi oleh pelaksana kegiatan agar mendapatkan arahan secara langsung.

Alat-alat yang dibutuhkan dalam pelatihan pembuatan Hidroponik Botol Bekas :

1. Gunting

2. Pisau pemotong

3. Solder

Bahan yang diperlukan dalam pelatihan pembuatan Hidroponik Botol Bekas :

1. Botol bekas

2. Kain flannel

3. Spons

4. Bibit tanaman

5. Nutrisi tanaman

6. Pecahan bata/ arang sekam (media)

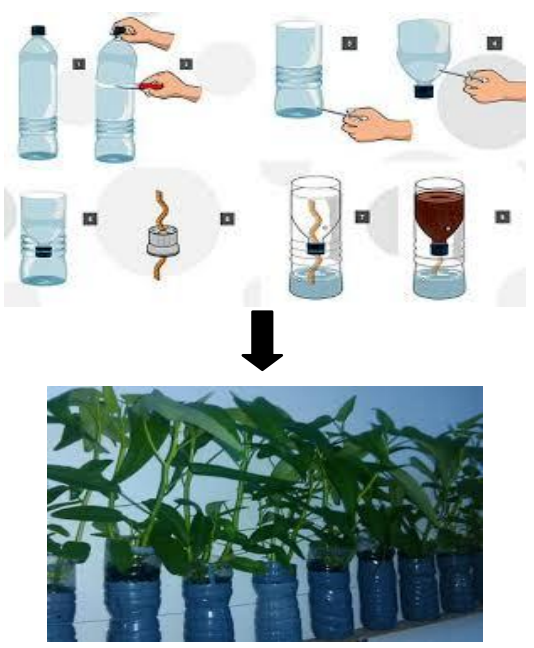



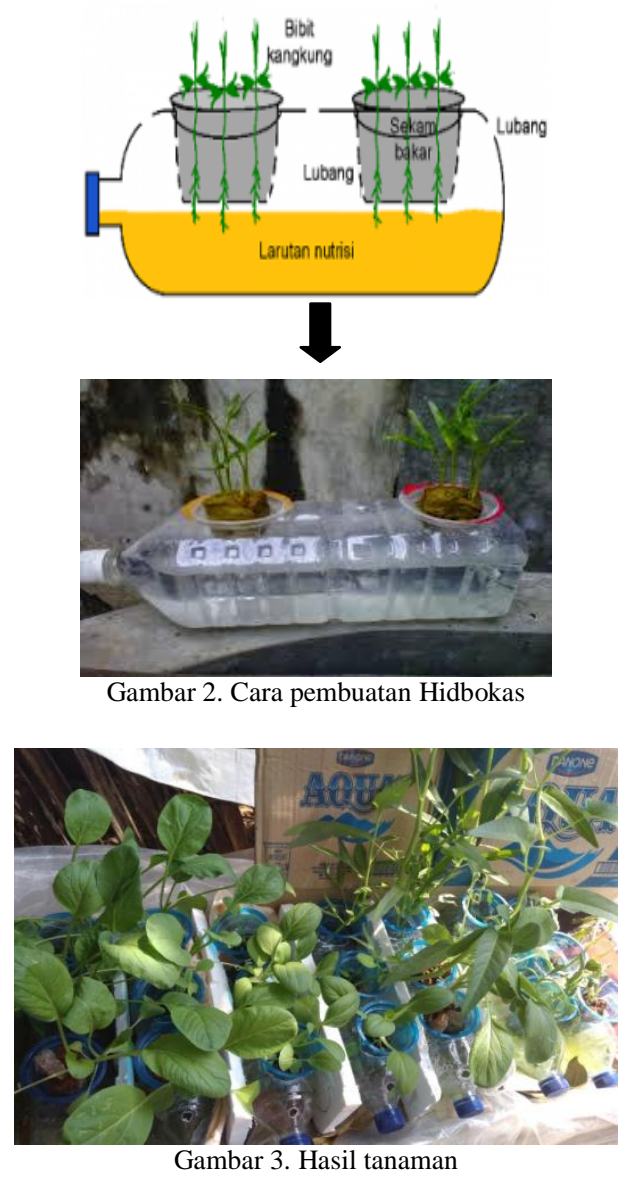

Pelaksana memberikan materi tentang kewirausahaan dan langsung mengaplikasikannya kepada masyarakat. Menjual hasil produksinya secara langsung ke masyarakat serta mendistribusikan ke toko tanaman dan bunga yang ada diwilayah kabupaten magetan dan sekitarnya. Selain itu juga akan membuatn brosur, pamflet, dan leaflet tentang produk yang mereka hasilkan, sehingga produk mereka akan lebih banyak dikenal dimasyarakat. Tidak hanya demikian, untuk memperluas pemasaran, kami juga akan membuat sebuah website jual beli mengenai produk yang telah di hasilkan. Agar pemasaran dapat dilakukan secara maksimal sehingga menghasilkan keuntungan financial.

Para peserta sangat antusias. Terlebih saat tim pelaksana membagikan bibit tanaman dan nutrisi untuk dibawa pulang dan dapat dipraktekkan sendiri di rumah. Para peserta juga mendapat pembekalan mengenai pengelolaan keuangan rumah tangga. Tidak hanya praktek, namun secara teori juga disisipkan materi yang juga dapat diterapkan oleh peserta.

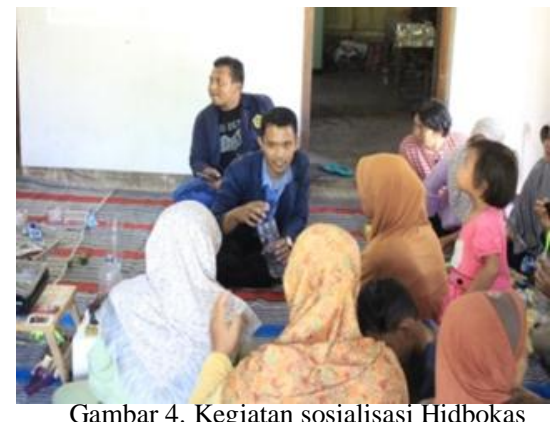

Tahap berikutnya di akhir kegiatan, tim melaksanakan Monitoring, dimana melakukan pengawasan dan pengecekan terhadap perkembangan hidroponik yang mereka buat. Mengidentifikasi permasalahan-permasalahan yang ada selama proses perkembangan, dan melakukan penyempurnaan terhadap hasil dari hidroponik. Sehingga mutu dan kualitas tanaman hidroponik pada masyarakat Desa Ngadirejo akan senantiasa terjaga. 
Website : http://dayamas.unmermadiun.ac.id/index.php/dayamas

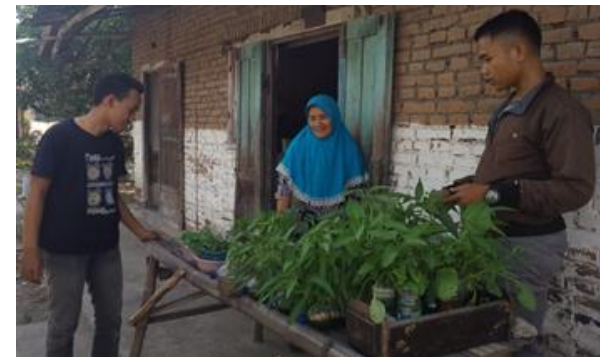

Gambar 5. Monitoring dan Evaluasi Kegiatan Hidbokas dengan Peserta

\section{III.HASIL DAN PEMBAHASAN}

Terciptanya kegiatan pelatihan HIDBOKAS "Hidroponik Botol Bekas", yaitu melalui kegiatan sosialisasi mengenai pemanfaatan limbah botol bekas menjadi media tanam hidroponik, dengan tujuan untuk menciptakan ekonomi kreatif serta pemanfaatan limbah botol bekas pada kelompok PKH Desa Ngadirejo Kec. Kawedanan Magetan. Kegiatan ini berfungsi untuk menambah pengetahuan baru terhadap masyarakat, serta dapat meningkatkan perekonomian masyarakat.

HIDBOKAS "Hidroponik Botol Bekas" tidak hanya dapat dikembangkan pada kelompok PKH Desa Ngadirejo saja, akan tetapi dapat dikembangkan untuk semua masyarakat khususnya masyarakat kota yang terdapat banyak limbah botol plastic. Tentunya dengan melibatkan dari pihak-pihak terkait seperti pemerintah serta masyarakatnya sendiri dalam meningkatkan ekonomi kreatif dan dapat mengurangi limbah plastic.

Hasil analisis dan Keekonomian HIDBOKAS :

Dalam pembuatan HIDBOKAS per 1 anggota kelompok ( 25 botol/budidaya) selama 1 tahun diperkirakan akan bisa budidaya 12 kali setiap 1 bulan panen. Per botol bisa menjadi 1 ikat dengan harga Rp. 3.000 dengan perinciaan :

- nutrisi : Rp. 12.000

- bibit tanaman : Rp. 7000 per jenis

Dalam 1x panen mengeluarkan modal

- nutrisi 1 x Rp. $12.000=$ Rp. 12.000

- bibit tanaman 3 x Rp. $7.000=$ Rp. 21.000

Total $=$ Rp. 33.000

Perhitungan (setiap panen):

Asumsi menanam 50 botol

50 x Rp. $3000=$ Rp. 150.000

Keuntungan Rp. 150.000 - Rp. 33.000

$=$ Rp. 117.000

\section{IV.KESIMPULAN}

Sosialisasi dan pelatihan system tanam dengan hidroponik yang dilaksanakan di Desa Ngadirejo berjalan secara lancer dan mendapat respon yang baik dari peserta. Kegiatan ini tentunya perlu mendapat perhatian dari pihak pemerintah desa agar keberlanjutan kegiatan ini bisa diambil alih untuk mendapat pendampingan dari desa.

Selain bermanfaat dari segi ekonomi dengan memberikan tambahan penghasilan bagi peserta yang mempraktekkan kegiatan ini, menanam hidroponik dengan media botol bekas ini juga berperan dalam mengurangi limbah botol plastic di lingkungan sekitar.

\section{UCAPAN TERIMAKASIH}

Terimakasih disampaikan kepada KEMENRISTEKDIKTI yang telah mendanai kegiatan PKM kami, kemudian ucapan terima kasih juga kami sampaikan kepada Dosen Pembimbing Ibu Dian Pratiwi, S.E, M.M yang senantiasa membimbing kami dari awal sampai akhir kegiatan PKM dilaksanakan. Serta perangkat Desa Ngadirejo Kec. Kawedanan Magetan dan Pembina PKH Magetan serta semua warga yang ikut terlibat dalam kelancaran program PKM ini.

\section{VI.DAFTAR PUSTAKA}

Istiqomah, S. (2006). Menanam Hidroponik. Azka Press: Jakarta.

Lingga, P. (2002). Bercocok Tanam Tanpa Tanah. Penebar Swadaya: Jakarta.

Suryanto, Ari, dkk. (2005). Kajian Potensi Ekonomis dengan Penerapan 3R pada Pengelolaan Sampah Rumah Tangga di Kota Depok. 